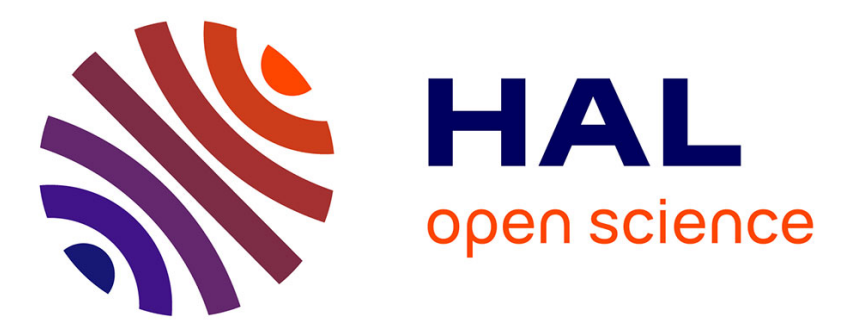

\title{
An In-Process BSR-Noise Detection System for Car Door Trims
}

\author{
Woonsang Baek, Duck Young Kim
}

\section{To cite this version:}

Woonsang Baek, Duck Young Kim. An In-Process BSR-Noise Detection System for Car Door Trims. IFIP International Conference on Advances in Production Management Systems (APMS), Aug 2018, Seoul, South Korea. pp.35-38, 10.1007/978-3-319-99707-0_5 . hal-02177851

\section{HAL Id: hal-02177851 \\ https://hal.inria.fr/hal-02177851}

Submitted on 9 Jul 2019

HAL is a multi-disciplinary open access archive for the deposit and dissemination of scientific research documents, whether they are published or not. The documents may come from teaching and research institutions in France or abroad, or from public or private research centers.
L'archive ouverte pluridisciplinaire HAL, est destinée au dépôt et à la diffusion de documents scientifiques de niveau recherche, publiés ou non, émanant des établissements d'enseignement et de recherche français ou étrangers, des laboratoires publics ou privés. 


\title{
An in-process BSR-noise detection system for car door trims
}

\author{
Woonsang Baek ${ }^{1[0000-0003-0353-2291]}$ and Duck Young Kim ${ }^{1 *[0000-0003-0072-4693]}$ \\ ${ }^{1}$ Ulsan National Institute of Science and Technology, Ulsan, South Korea \\ *dykimeunist.ac.kr
}

\begin{abstract}
The Buzz, Squeak, and Rattle (BSR) noises coming from car body parts are often caused by defective assembly. This paper presents an in-process BSR noise detection system for car door trims. A car door trim is slowly pressed down by a pneumatic pusher, and then the acoustic signals measured right above the door trim and on the four corners of the noise detection workstation are monitored for noise source localization by the time difference of arrival method and the relative signal strengths. Finally, the energy of BSR noise is examined by the discretized frequency information of the localized signals.
\end{abstract}

Keywords: In-process measurement, Inspection, Car door trim.

\section{Introduction}

It has been reported that weak but still irritating noises coming from car body parts could disturb driver's attention, thereby incurring potential warranty claims. These noises are usually caused by the friction and irregular contact of mating surfaces between car parts due to defective parts, miss alignment, and incomplete assembly and called as BSR(Buzz, Squeak, Rattle) noises [1]. Many automakers thus have conducted sampling inspections by using an artificial vibration generator in an anechoic chamber.

This paper presents an in-process BSR noise detection system for car door trims. We estimate the BSR noise source by the time difference of arrival method and the relative signal strengths. The energy of BSR noise is examined by the discretized frequency information of the localized signals. The practical test results with real car door trims provide empirical support for the detection performance of the developed system.

\section{System configuration}

The in-process BSR noise detection system was developed by consisting of (i) a sensor array of nine microphones, (ii) four parabolic microphones, (iii) a pneumatic pusher controlled by a gantry robot, (iv) a data acquisition system (NI cDAQ-9178 ${ }^{\mathrm{TM}}$ ), and (v) a noise detection software. 


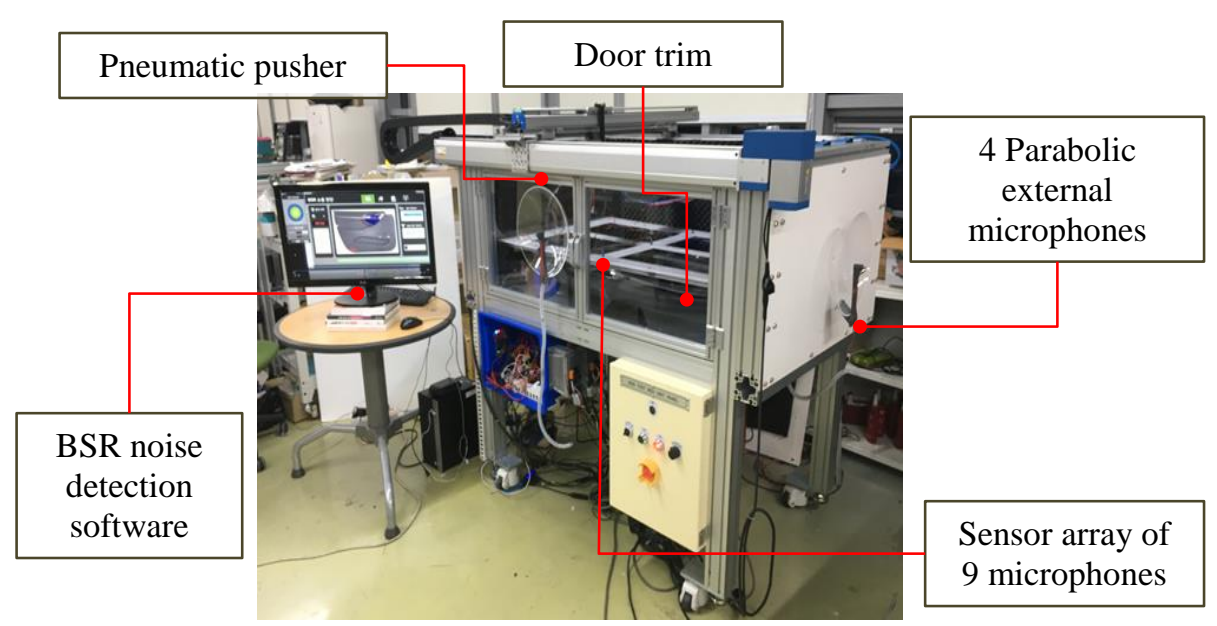

Fig. 1. The in-process BSR noise detection system.

A car door trim is slowly pressed down by a pneumatic pusher, and we collected the acoustic signals measured right above the door trim by a microphone array (called internal signals). Also the ambient sounds are collected with parabolic microphones on the four corners of the noise detection workstation.

\subsection{Data acquisition}

The proposed in-process BSR detection procedure consists of the three main phases: (i) noise reduction, (ii) noise source localization, and (iii) abnormal noise detection. First, internal signals and external signals are collected from the sensor array and the parabolic microphones respectively. The inspection process noise, for example, movement noises of the pneumatic cylinder and actuators, was collected during the real inspection processes with a healthy car door trim for each 2 seconds recording time.

\subsection{Noise reduction}

The objective of this step is to reduce the external noises from the collected internal signal. In order to subtract the spectrum of the external noises, we apply a spectral subtraction method with the predefined attenuation factors. The spectrum of the denoised signal is then given by the multiplying the spectrum of internal signals and the attenuation factors. The attenuation factors here can be obtained by using the average of the time-frequency coefficients of the internal signal. However, in order to minimize musical noise after spectral subtraction, we used the empirical Weiner attenuation rule and can get the $\mathbf{S}$, the spectrum of denoised signal as follows [2]:

$$
\mathbf{S}=\left(1-\lambda\left[\frac{1}{\xi+1}\right]^{\beta_{1}}\right)^{\beta_{2}}
$$


where the over-subtraction factors are $\beta_{1}, \beta_{2} \geq 0, \lambda \geq 1$, and $\xi$ is signal-to-noise ratio of the power spectrum. Note that we used the soft-thresholding method for determining the over-subtraction factors, and hence the following values are specified: $\beta_{1}=$ $0.5, \beta_{2}=1$, and $\lambda=5$.

\subsection{Noise source localization}

To examine the existence of unknown external noise, we localize noise sources by applying a hyperbolic function with the Time Difference Of Arrivals (TDOA) method, which is widely used for estimation of noise source location [3, 4]. We obtain a hyperbola by using the position information of a pair of microphones in the array and the arrival delay time. Generalized Cross-Correlation with Phase Transform method (GCCPHAT) [5] is employed for efficient computation of delay time of arrival for noisy data.

Note that a hyperbola here implies the loci of possible locations of a noise source from the perspective of the total nine pairs of microphones. Then, we finally identify the location of a noise source by computing the average of intersection coordinates between all hyperbolas.

We consider that powerful source exists inside of the station. If the estimated location is outside of the array, we consider the powerful source exists outside of the station.

\subsection{Abnormal noise detection}

We investigate the existence of unknown internal noise in the denoised signal. To do this, the average energy of the signals captured during the 150 times inspection processes with a healthy car door trim is used as a reference.

The reference energy information for all microphones are compared with the energy information of the current localized internal signal. Any significant difference between the two energy information will lead us to conclude that an unknown internal noise, i.e. BSR noise, is detected.

\section{Experimental results}

Table 1. The experimental results of the total 192 inspections.

\begin{tabular}{ccc}
\hline & Faulty door trim & Healthy door trim \\
\hline Hit & 93 & 0 \\
Miss & 3 & 0 \\
False alarm & 0 & 9 \\
Correct rejection & 0 & 87 \\
Total & 96 & 96 \\
Correct decision (\%) & $96.8 \%$ & $90.6 \%$ \\
\hline
\end{tabular}


We conducted the inspection experiments with two types of car door trim: a faulty door trim known to emit a BSR noise and a healthy door trim. The inspection was done 96 times for each type of door trim. The result summarized in Table 1 shows that the correct decision rates for the faulty and the healthy door trims are $96.8 \%$ and $90.6 \%$ respectively. Nonetheless, the number of incorrect decisions cannot be negligible. As mentioned earlier, the spectral subtraction still left musical noises that often result in arbitrary energy value of a signal. Therefore, for the future study, we need to enhance the spectral subtraction method and develop a more detailed energy representation method for a signal.

\section{Conclusion}

This study presented the in-process BSR noise detection system for car door trims, which analyses acoustic signals acquired by a microphone array and parabolic microphones. The signal analysis was carried out by noise reduction and localization using a spectral subtraction method and a hyperbolic TDOA approach, followed by abnormal internal noise detection by the energy comparison of signals. The total 192 inspection results with real car door trims demonstrated the detection performance of the developed system.

For the future study, we will enhance the noise reduction method and develop a more detailed energy representation method for a signal. The localization method was applied only to check for the presence of external noise sources in this study. We will develop the method that can precisely estimate the defect location of the product in the process. We will also validate the system configuration by rearrangement of microphones and redesign of the pneumatic pusher.

\section{References}

1. Trapp, M., Chen, F.: Automotive Buzz, Squeak and Rattle: Mechanisms, Analysis, Evaluation and Prevention. Butterworth-Heinemann, Boston, USA (2011).

2. McAulay, R., Malpass, M.: Speech Enhancement Using a Soft-Decision Noise Suppression Filter. IEEE Transactions on Acoustics, Speech, and Signal Processing 28, 137-145 (1980).

3. Gustafsson, F., Gunnarsson, F.: Positioning Using Time-Difference of Arrival Measurements. Proceedings of 2003 IEEE International Conference on Acoustics, Speech, and Signal Processing, vol. 6, pp. 553-556. Hong Kong (2003).

4. Mensing, C., Plass, S.: Positioning Algorithms for Cellular Networks Using TDOA . Proceedings of 2006 IEEE International Conference on Acoustics, Speech and Signal Processing, vol. 4, pp. 513-516, Toulouse, France (2006).

5. Knapp, C., Carter, G.: The Generalized Correlation Method for Estimation of Time Delay. IEEE Transactions on Acoustics, Speech, and Signal Processing 24, 320-327 (1976). 